\title{
EDITORIAL
}

\section{Open Access, Peer Reviewing and Quality of Research Publications}

\section{T. Ramanan \\ Editor of JULA}

Introduction: Primary objective of scientific publications is to disseminate knowledge among researchers and stakeholders of academic investments. Documentation and dissemination of information are being evolved with the aid of emerging technologies in publishing businesses. This amounts to substantial degree of cost incurred with knowledge dissemination, which is further challenging the libraries around the globe that strive to find the balance between demand and supply of information. Since scholarly publication has become commercialized and is gradually taking the core element of academic writing away from the purpose of knowledge-sharing, the library professionals ought to channel the flow of information from its inception to the use, in order ensure credence.

It was argued that research output and academic publications should be accessed freely online as long as they were publicly funded (Hanel, 2015). This holds true to Sri Lankan university library context since the university education is substantially funded by the government. In addition, research is supported through incentives and grants by the ministries to promote research and publication by academics. Therefore, it is university librarians' sheer responsibility to promote open access publishing to make the process of knowledge dissemination efficient.

Open Access (OA): With the emerging technological advancement, the open access movement was formed in the early 1990 s, as a remedy to stringent budget cuts in academic libraries (Hanel, 2015). Open Access (OA) movement was initiated in Britain and expanded by the Public Library of Science (PLoS) to eliminate obstacles between users and sources (Schekman, 2015).

Since the user-needs compel the importance of free access to published research works, the individuals and institutions are mounting their unanimous 
interest in open access resources. To accomplish this purpose in the country Sri Lankan Journals Online (SLJOL) serves as a hub to such open access resources published from within Sri Lanka (Ranasinghe, 2014).

Since university libraries in Sri Lanka are facilitated with satisfactory level of Internet connection that provides access to unimaginable amount of electronic resources, the open access movement will increase the extent of access to credible academic publications. Most importantly, unrestricted access to electronic information resources will ensure the materialization of research output since the audience will have adequate grasp of subjects of their interest. In this line, research development is steadily increasing with unnecessary repetition of same research.

Being open in access to academic publications is not as simple as it seems. The expenditure involves in handling of received articles should be borne by the publishing body. Few renowned journals with high subscription rates do often have the grip of quality as they restrict the number of essays they publish per issue. These luxury journals have a permanent panel of referees who are paid for reviewing.

Predatory publishing: Quality of academia does not always necessarily depend on the number of papers published or citations received since considerable number of published works had been disputed for their credibility and plagiarized pieces. This situation fuelled when academics and researchers are publishing in light of receiving rewards and grants rather than disseminating the knowledge. Many dubious journals and publication are on the Internet and in book stores, without undergoing approved intellectual assessment. This situation insists upon the importance of enforcing quality control on academic publication that might imply additional costs and time.

Not only does the predatory publishing is hardly contributing to the development of knowledge corpus but also it increases the information overload, which becomes 'noise' in information searching. Hence, the predatory publishing should be controlled by appropriate legal measures and quality evaluation in which, librarians have major role to play in the quality assessment of the publications. 
Quality of publishing: To be largely cited, an author needs to publish his/her works in most reputed, multi-disciplinary journals that comprise of the apex of publication hierarchy. On the next tier stand the journals of different specialization that are discipline-specific. Large numbers of heterogeneous and unselective journals remain in the bottom of this pyramid (Nature, 2006).

Prestigious and luxury journals are serving as the platform for quality publications, though they are not the only means of publishing outstanding research. It is feared that publishing business has distorted the proxy of quality in scientific research (Schekman, 2013). Besides, predatory publishing by individuals and mushroom journals has adversely been affecting the quality of scholarly communication.

Lawrence (2003) emphasizes on the responsibility of writers, referees and editors in protecting the quality of research and its publication. Rigorous and double-blind peer reviews, which are essential to ensure the quality, are on the other hand, cost-incurred and time-consuming processes. Nevertheless, peer review does not necessarily warrant the quality of publication (Nature, 2006a) and could be flawed by biased and incompetent reviewing. Therefore, editors and reviewers must vow to perform their tasks as an inevitable obligation to the development of intellectual sphere.

Peer reviewing: Quality in research publication does not omit the responsibility of peers in assessing the scholarly achievement. Reputed journals have appointed panels of paid referees whereas many other journals do not have privilege to pay their reviewers. Depending on the purpose, resource strength and discipline publishers employ different types of peer reviewing.

There are three main types of peer reviewing, which are single blind, double blind and open peer reviewing. In single blind peer reviewing, the review(s) are kept anonymous from authors, whereas in double-blind peer reviewing both authors and reviewers are concealed from each other (Royal Society, 2011). In this regard, indiscriminative, highly dedicated blind-reviewing promisingly contributes to the quality of entire scholarly world. 
On the other hand, open peer reviewing, being an experimental method (Royal Society, 2011), is helpful to enlighten the beginners of academic writing. While open peer review constitutes advantages, Khan (2010) argues that the process is not fair and more likely to be biased, especially when the peers are from within the same institute. Furthermore, researchers are reluctant to execute open peer review technique (Nature, 2006b). Although it ensures the transparency in reviewing, the open-peer review has room for bias either through personal influence or professional intimidation.

Prospects: Despite the amount of inaccurate, biased and unwarranted information on the web, it serves as a unanimous source of scholarly communication to academic writers and researchers. Provided the number of electronic information resources is exponentially increasing by each second, it is the responsibility of academics, reviewers and editors of scholarly publication to guarantee the quality in knowledge dissemination.

Most importantly, authors must realize the importance of constructive criticism on their works, regardless of the writer's academic excellence and experience. Meanwhile, experienced researchers and academicians are expected to encourage possible critical discussions on papers presented at symposia and conferences, where authors have opportunity to improve their scholarly communication. As a result of which, researchers will find their ways in publishing their works in prestigious journals.

Besides, open access to scholarly publications must be considered as a gesture to ensure democratic use of information, without causing any infringement to intellectual property rights.

In this regard, role of Sri Lankan academic libraries could extend to formation of a bureau of experts in library and information sciences to culminate the quality of local publications. Therefore, Standing Committee on Library and Information Sciences (SCOLIS/UGC) is holding potentiality to take initiatives in drawing standards on assessment and publication of scholarly works in the country. 


\section{References:}

Arms, W.Y. (2002). What are the alternatives to peer review? Quality control in scholarly publishing on the web. The Journal of Electronic Publishing, 8 (1). doi: http://dx.doi.org/10.3998/3336451.0008.103

Hanel, S. (2015). Open Access and No End. Retrieved from http://www.lindau-nobel.org/open-access-and-no-end/ (Accessed on 15 October 2015).

Khan, K. (2010). Is open peer review the fairest system? No. The BMJ, 341. doi: http://dx.doi.org/10.1136/bmj.c6425

Lawrence, P.A. (2003). The politics of publication. Nature, 422, 259-261. doi:10.1038/422259a

Nature (2006a). Quality and value: The true purpose of peer review. Nature. doi:10.1038/nature05032

Nature. (2006b). Nature's peer review trial. Nature.doi:10.1038/nature05535.

Ranasinghe, W.M.T.D. (2014). Sri Lanka Journals On Line (SLJOL) Project: Increasing global visibility of local research output. SLSTINET Seminar on Open Access to Research Information, 18 February, 2014. Retrieved from http://dl.nsf.ac.lk/handle/1/11401 (Accessed on 07 November 2015)

The Royal Society (2011). Peer review. Retrieved from http://www.publications.parliament.uk/ pa/cm201011/ cmselect/cmsctech/writev/856/m69.htm (Accessed on 14 October 2015)

Schekman, R. (2015). Publishing the most important work in the lifesciences. $10^{\text {th }}$ Munin Conference on Scholarly Publishing, November 29 - December 01, 2015, Tromso. doi: http://dx.doi.org/10.7557/ 5.3661

Schekman, R. (2013). How journals like Nature, Cell, and Science are damaging science. Retrieved from http://www.theguardian.com/ commentisfree/2013/dec/09/ how-journals-nature-science-celldamage-science (09 November 2015) 